\title{
Design and Development of VH-iSTEM Learning Strategy on Geometric Thinking: An Experts' Evaluation
}

\author{
Hassan Muhammad Nasiru, Abdul Halim Abdullah, Ismail Norulhuda
}

\begin{abstract}
In the $21^{\text {st }}$ century, the process of teaching and learning STEM subjects must shift from teacher-centered dominated learning process to students-centered. In this process, students can actively carry out the learning activity and make an experiment to reach their own conclusions. For this reason, this study designed a learning strategy on geometry called VH-iSTEM learning strategy through connections between the iSTEM approach, particularly the engineering design with van Hiele phases to help students improve their geometric thinking skills. Three basic skills in geometric thinking consisting of visualization, analysis, and informal deduction that covered triangles and quadrilaterals are considered in this study. The five-phase instructional model called ADDIE model was adopted in the whole process of design and development of the VH-iSTEM learning strategy. The researchers used quantitative and qualitative approaches to analyze the experts' feedback on the suitability of the connections between the two phases, the activities provided, and the materials used. Also the VH-iSTEM learning strategy was tested on 30 students to ascertain its effectiveness based on the students' level of thinking. The result indicated that VH-iSTEM learning strategy was pedagogically functional and effective in improving the geometric thinking skills of students. The researchers used only one group of students to determine the levels of thinking skills. This study is unique based on its ability to connect engineering design with van Hiele phases in learning school geometry.
\end{abstract}

Keywords : iSTEM approach, van Hiele level of Thinking.

\section{INTRODUCTION}

Geometric thinking skills are considered to be the backbone of mathematics education and a component that contributes to other disciplines like engineering, science, and technology in general. Evidence abounds that, Geometric thinking skills are considered as the pre-requisite knowledge that are needed to enhance ideas, experience in some specializations like engineering, architectures, chemistry, among other disciplines (Georg, 2012; Abdullah \& Zakaria, 2013b; Gronmo et al., 2016). In other words geometry is the

Revised Manuscript Received on October15, 2019

* Correspondence Author

Hassan Muhammad Nasiru*, Science Education department, Sokoto State University, Sokoto, Nigeria. mohammad.nasiruhassan@ssu.edu.ng

Abdul Halim Abdullah, Science, Mathematics \& Creative Multimedia Education Department, Universiti Teknologi Malaysia, Johor Bahru. Email: p-halim@utm.my

Ismail Norulhuda, Science, Mathematics \& Creative Multimedia Education Department, Universiti Teknologi Malaysia, Johor Bahru, Malaysia. Email: p-norulhuda@utm.my impetus that stimulates and helps other disciplines, to explore innovations and ideas in order to provide solutions to problems for the benefit of humanities. From an international perspective, the National Council of Supervisors of Mathematics (NSCM), considered geometry as one of the essential mathematics knowledge needed in the twenty-first century, and that students required the knowledge of geometry to thinking in order to function effectively for the development of the world. Carl, (1989) pointed that this could be achieved if students are given chance to learn and understand the properties of different shapes (plane \& solid) and should be given chance to visualize and verbalize these objects, by exposing them to (activity-based learning) problem-solving skills. In spite of the significant importance of geometry, the persistence of difficulty in learning geometry and the low level of GT demonstrated by the students continues to be the topical issues in mathematics education as difficult areas, hard to understand and abstract in nature, not only in Nigeria. Similar problems were observed in some countries as pointed out in the literature (Abdullah \& Zakaria 2013; Alex \& Mammen, 2016; Ogan \& George, 2015; Usiskin, 1982; Vojkuvkova, 2012).

In Nigeria, New General Mathematics Curriculum (NGMC) has given and recognized geometry at all levels of education, and also the objectives in the Mathematics curriculum considered geometric thinking (GT) in both basic levels ( lower, middle and upper basic) and senior secondary schools (Federal Republic of Nigeria, 2012a). Also, the curriculum has given emphasis on three basic geometric thinking (GT) skills in learning school geometry that include identification, properties, relationship and differences among plane and solid shape (Federal Republic of Nigeria, 2012a). This indicated the presence of level 1-3 of van Hiele levels of GT [11]. On top of that for example, the formula derivations are also emphasized in the basic level while proofs of theorem are emphasized in senior secondary school. Students will be guided to use deduction or step-wise logical reasoning to arrive at a valid conclusion as stated in the document of the Nigerian curriculum (Federal Republic of Nigeria, 2012a).

In the analysis of Nigerian mathematics curriculum, Atebe (2008) pointed that the Nigerian mathematics curriculum like other mathematics curricula in the world emphasized on basic geometric thinking skills that include the construction, the properties, and relationship between various geometric shapes; the skill of proving theorems in school

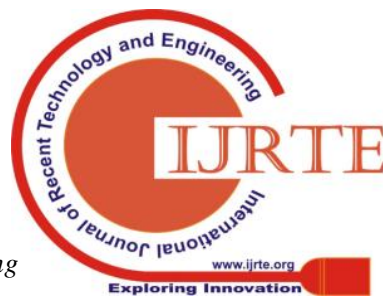


Geometry; and the skill of solving riders based on the theorems. Thus, this has been done to develop the students geometric thinking for them to understand the relationship that exist among objects, shapes or things; and use the ideas for innovations in solving societal problems.

The manifestation of students' poor performance, difficulties and low level of geometric thinking (GT) in Nigerian secondary schools remained challenging issues. There are instances where students cannot apply basic concepts which are level one of GT (van Hiele level of geometric thinking) and application of theorems ( level four of GT) in solving the geometric problem, and many avoid answering questions related to geometry as affirmed by highest secondary school examination body in West African Countries [13]-[18]. And also confirmed (Azuka, 2014; Ogan \& George, 2015). Atebe (2008) affirmed that only $2 \%$ and $3 \%$ of Nigerian students achieved level $2 \& 3$ and that $57 \%$ are at level 0. Difficulties encountered by Nigerian students in geometry and lower levels of geometric thinking skills are connected with the learning strategies used.

Thus, this problem may be connected to the nature of teaching geometry and learning process which is traditional, where school geometry is presented and learned based on definitions, axioms, and theorem for learners to memorize. In other words, the delivery of the lesson is based on transmission and absorption. It is evident that learning strategy in Nigeria does not give students the opportunity to learn geometry with understanding but rather students are made to memorize fact in learning geometry (Agwagah 2005).To supported this Atebe \& Schäfer (2011) maintained that the teaching and learning geometry in Nigeria remained traditional not in line with the VHPL. It is affirmed based on the analysis, of the sample teachers in Nigeria which indicated $80 \%$ of the lesson are dominated by the teachers without the active involvement of the learner or $35 \mathrm{~min}$. out $40 \mathrm{~min}$. are taken by the teacher (ibid). Substantial research in recent studies shows that the teaching and learning process in Nigerian schools remained traditional [21]-[23]. Thus, it contradicts the document of the Nigerian mathematics and National Policy on Education (NPE), that the teaching and learning process should involve the use of activity (the real-life application) in relation to geometric concepts and mathematics in general.

Thus, this could be one of the geneses of students' failure to gain the needed knowledge or experience that can enhance their GT and also which can be the bases of the low level of GT in Nigeria. To support this, Hiele (1999) affirmed that teaching school geometry based on formal deduction ( definitions, axiom, and theorems) and assuming that students think based on the formal deduction creates gaps between the students' levels of GT and the geometry that is expected to learn. This is because they lack the prerequisite knowledge and understanding of basic geometric skills. It is based on this, Hiele (1999) supported Piaget on his statement " given no education is better than giving it at the wrong time". However, very few researches in Nigeria investigated the GT levels and also investigate learning strategies in line with VHPL to enhance the GTL of the learners.

Literature indicates that teaching geometric thinking required teachers to engage the learners with the appropriate

task, manipulative that can give them a sense of relationship that exists among geometric shapes and able to recognize the properties in relation to a particular situation ( real-life) [24]. More so, this could enable the learners to reason solely on the basis of the properties (Andy, Geoff, Sue Johnston, Francis, Mason, et al., 2005, page 113). In other words, the learning of geometric thinking required the use of the real-life application (hands-on activities) for learners to have a direct viewing of the geometric figure in relation to his environment, which could help in developing positive ATLG; understanding of the shapes and logical reasoning respectively. Development of geometric thinking (GT) begins with play, students who are engaged with activities and games will be able to successfully achieved higher GT developed by Euclid [11]. Hands-on activity, reflective, and interactive experiences are very important and a key to good geometry activities at the elementary and middle school levels [25].

In an effort to change the teaching of mathematics for a better understanding of students in Nigeria, the National Mathematics Centre Abuja (NMC) introduced the Activity Learning Approach [26]. An activity-based approach is a child-centered approach (Dorojaiye, Salman, Jekayinfa, Okwuoza, 2016). One of $21^{\text {st }}$-century learning strategy that shifted the dominant teacher-centered approach to student-centered learning is the integrated STEM approach [28]. Kelley \& Knowles (2016) noted that one of the potentials of the iSTEM approach is the ability to provide the situated learning approach, where the learners develop learning experience or skills through activity. Van Hiele specifically indicated that students can be best understand school geometry if they are given chance to play with shapes and given them challenging activities that involve the construction of patterns, use of puzzles and hands-on activity. And maintained that in this approach students geometric thinking will be improved from lower to more advanced level of thinking in school geometry [11]. Therefore, the connection of the iSTEM approach in line with van Hiele phases to provide a well established learning activity could help the students to learn and master the skills needed to develop geometric thinking from lower level of thinking to a more sophisticated level of van Hiele level of geometric thinking.

STEM education provided instructional strategies which include research-based pedagogy; project or problem-based learning; scaffolding; technology integration, play-based pedagogy, (and engineering design) among others as reported (Australian Government Department of Education and Training under the Early Learning STEM Australia, 2016; Global STEM Alliance, 2016). However, in this research efforts were made to design and develop learning strategy using iSTEM based on engineering design process in connection with van Hiele phases of learning geometry and provide the learning strategy based on hands-on activity, challenging and provide the relationship between geometric concept and application in real-life with hope to help in developing interest, active participation of students to enhance the geometric thinking. 
Thus, the present research was done primarily for the purpose of developing learning strategy as an alternative to the current learning strategy used in learning school geometry among secondary schools in Sokoto state, with the hope to improve the geometric thinking of the learners. Thus, the overall picture of the research is based on five stages based on the ADDIE model that include Developments of learning strategy.

However, to ensure that VH-iSTEM learning follows the connection between integrated STEM approach (engineering design phases) and van Hiele phases of learning geometry base on the content and objective of basic secondary school Mathematics and its objectives, a guideline that was applied to the levels of geometric thinking in every lesson activity were provided. The figure 1 and 2 below provide the flow chart of learning activities based on the objectives and each level of thinking.

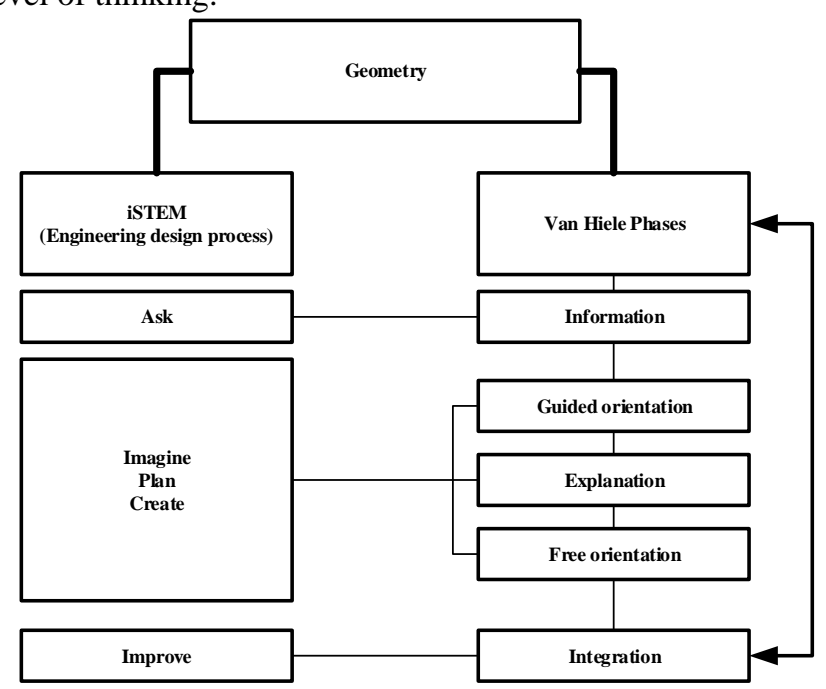

Fig. 1.iSTEM connection with van Hiele phases

\section{DEVELOPMENT OF VH-ISTEM LEARNING STRATEGY}

\section{A. Instructional design model (ADDIE)}

Instructional design is a complex process that required a systematic process and creativity in activity, interactions between teachers, students, and content. Therefore, to achieve the objective of the research, the ADDIE model was used in the process. The model-like other instructional model provides a systematic process for the development of any instructional strategy and helps educator to ensure that they are appropriately taught in the right and appropriate way [32]. ADDIE model consists of five phases that include, Analysis, Design, Development, Implementation, and Evaluation (Branch, 2009). The following figure provides the flow chart for the ADDIE model.

However, this paper focused only on the two final stages of the ADDIE model, implementation and evaluation by experts. To achieve the objective, a module based on three objectives in the Nigerian New Basic Mathematics Curriculum was used, covering only three-level of thinking in van Hiele theory. See table 1-5 for the result of experts based on the content organization, connections between the iSTEM and van Hiele phases and activities provided. Furthermore, the example of the activities at each level of geometric thinking is provided below.

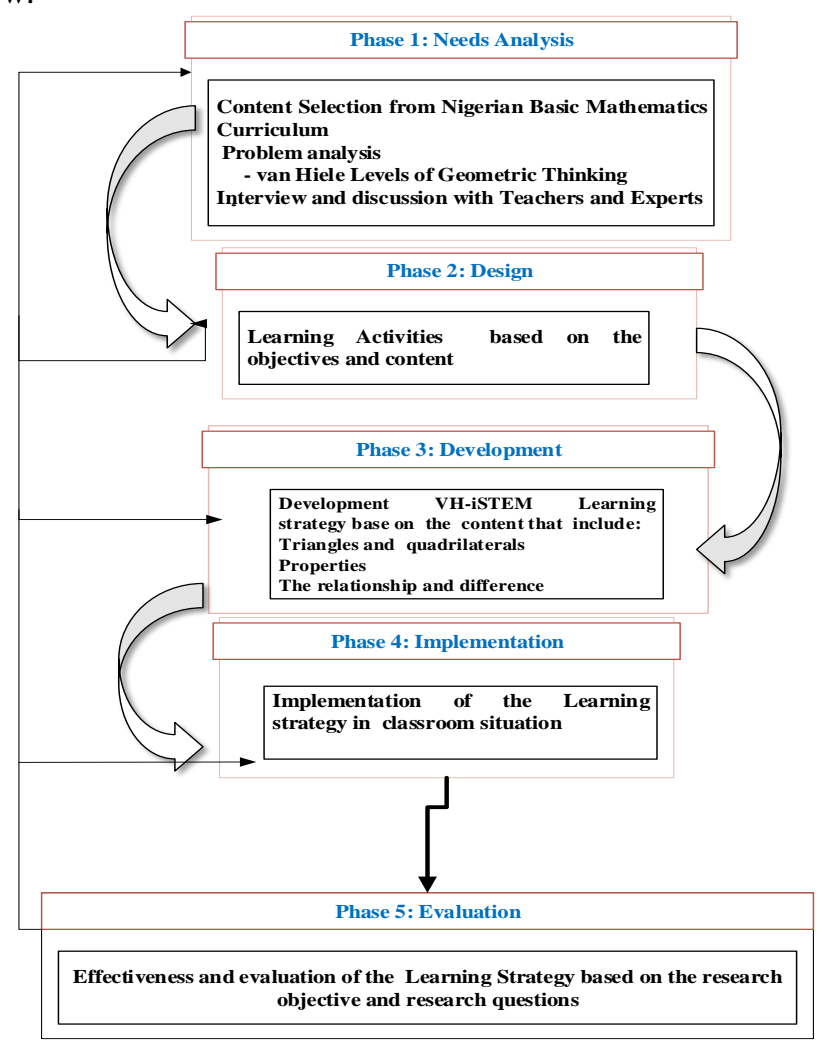

Fig. 2.Flow chart for the ADDIE model

\section{B. Objective one (based on van Hiele level 1)}

Students at this level are expected to identify and name the geometric shapes based on their appearance. The proposed activity involves an interactive discussion between teacher and students and among students themselves to assess the prior knowledge and link with the topic using a series of questions by the teacher. To concretize the discussions for better comprehension, students will do an activity to discover shapes that are triangular in nature (quadrilaterals) using physical observation in the classroom and outside. Thus, activity. the activities involve discovery of shape using physical observation (Scientific approach) of the geometric shape in the class/outside; drawing of the shapes discovered and construct (engineering) the shape using chopsticks, with glue gun and marching (Mathematical approach); use geoboard to draw the shapes with different orientation, and provide the appropriate names of the shapes base on physical appeal. See the possible activities base on the objective. 


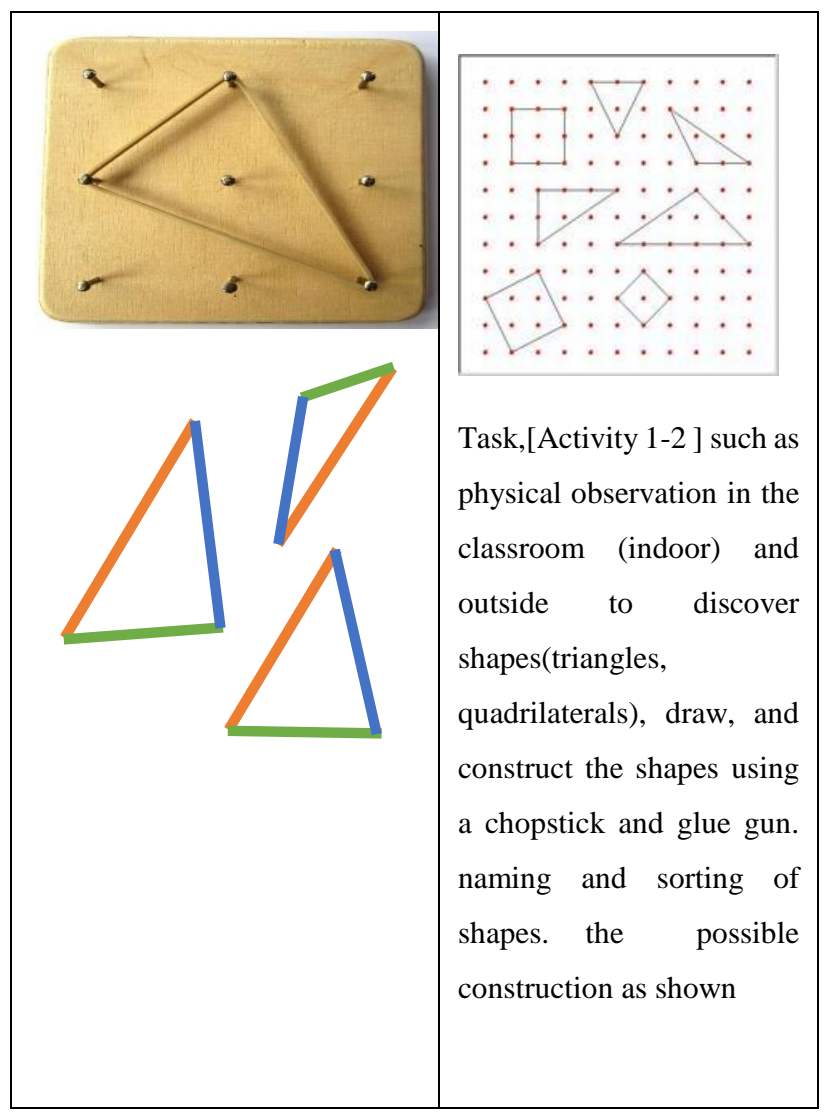

Fig. 3.photo type of the activity

\section{Objective two (based on van Hiele level 2)}

At this level, students begin to see and describe the triangles and quadrilaterals or geometric shapes based on identifying properties not in relation to another geometric figure. However, students at this level lack logical explanations, rather they use measurement, drawing and creating shapes using a concrete object to established or see relationships. To achieve these objective students will be involved in challenging activities to draw or create and construct different geometric shapes by joining or connection of two or more parts from the puzzle and students will be required to show their method using a different color. On top of that challenging activity to construction a possible pattern in developing a tile using geoboard and draw the pattern on the grid paper to show the pattern. Identification of the properties from the identified shape in the patterns by measuring using a ruler and Protractor ruler. Students will record their findings.

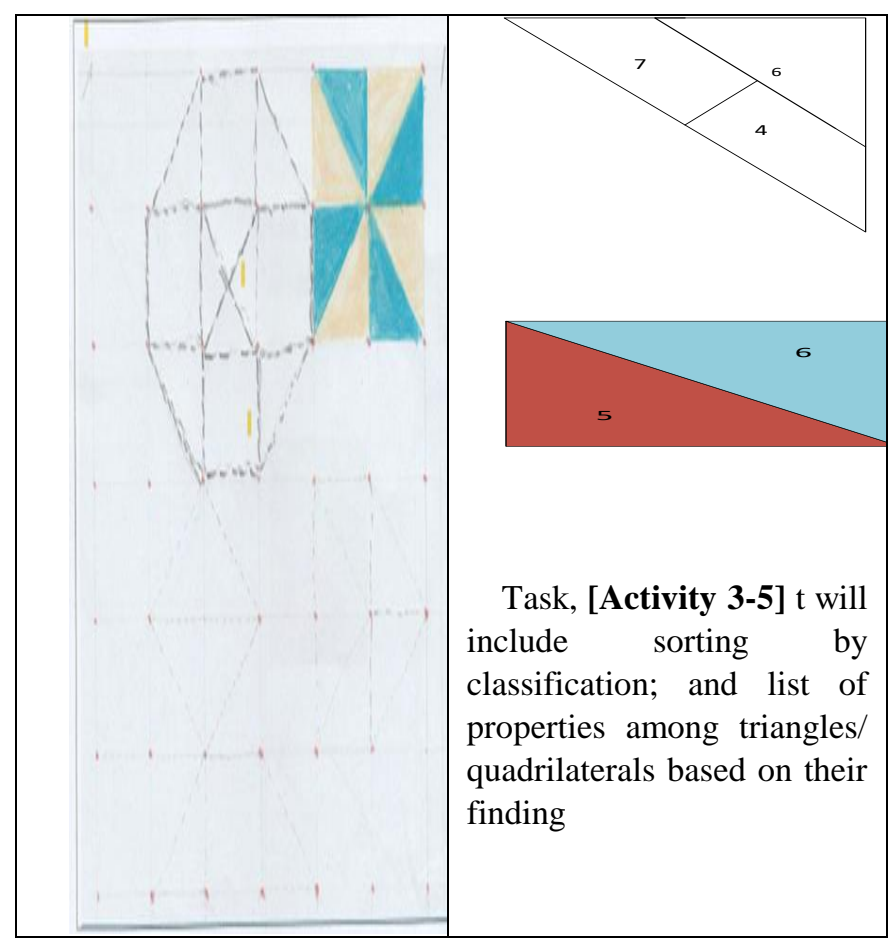

Fig. 4.Photo type of the activity

\section{Objective}

At this stage, the students begin to appreciate and see the connections among quadrilateral based on the properties and can order the geometric shapes based on simple argument, but lack formal understanding of proofs. In other words, the student reasoning is based on the nature of the geometric figure such as size, angle, the line among others. To facilitate the activities that help to achieve the objectives, students will be exposed to challenging and creative activities that involve the construction of geometric figure by joining midpoints of lines of a give figure to obtain a new figure and also to make a construction of what they usually see in their environments, such as Tower (Masts) poles with different shapes for example masts that are triangle, rectangle or square in nature using marshmallow and spaghetti.

Thus students will be made to identify, different shapes found in their construction, and makes informal justification about the relationship between shapes. Questions like what can you say to anyone to look for in order to identify rectangle in your construction? What similarities can you see between two shapes; what name will you call the figure you obtain by joining the midpoints and why is the name appropriate; what relation can you given between these two geometric shapes. Can you identified shape with four congruent sides and angle This type of question will be asked regarding other remaining quadrilaterals. See fig. 5, provided below 

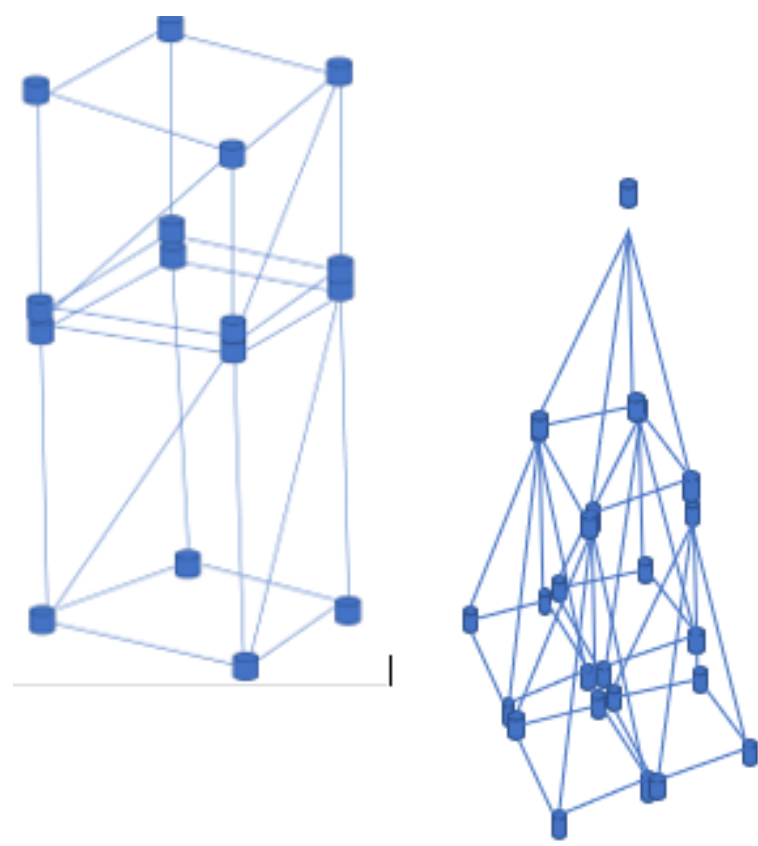

Fig. 5.Photo type of the activity

\section{STATEMENTS OF THE PROBLEMS}

The integrated STEM approach (iSTEM) in Nigeria is just at an emerging stage, although there is a call for teacher training, for example, call for teacher training in Science, Technology, and Mathematics (STM) in Sokoto State to update teachers' skills in classroom practice, and recommended extensive training that can provide strategies and methods in all STEM subject. Yusha (2015) also calls for a better learning strategy that provides understanding and meaningful learning in STM subjects in Sokoto state. This is because students in Nigeria are becoming increasingly boring and inattentive in their mathematics classroom as a result of the learning strategy used to explain mathematics concepts [33].

To fill in the gap and solve the problem, there is a need for better learning strategy that can provide meaningful, active participation, creativity, and develop geometric thinking skills. One of the current approaches used is integrated STEM education (iSTEM). The approach provides the means by which content can be learned with challenging activities that provides scenarios that students encounter in both informal and formal classroom settings and provide a relationship between instructional content and real-life application (Global STEM Alliance, 2016). Therefore, this study attempt was made to determine the validity of the developed learning strategy called VH-iSTEM which was develop based on the connections between the iSTEM approach (engineering design phases) and van Hiele phases of learning geometry before its effectiveness was determined in the implementation stage. More so, to ensure the achievement of module objective as well as the activities provided in the learning strategy a pre-test and post-test were conducted as suggested Meyer in [34].

\section{RESEARCH OBJECTIVESE}

The objective of this research is to explore the experts' validation of the VH-iSTEM learning strategy that involves the connections of the iSTEM approach (engineering design phase) with the van Hiele phase of learning geometry. In specific, the objectives are to:

- Determine the experts' validation about the VH-iSTEM leaning strategy and its activities.

- The effectiveness of VH-iSTEM learning strategy on students' levels of geometric thinking.

\section{THEORETICAL FRAMEWORK}

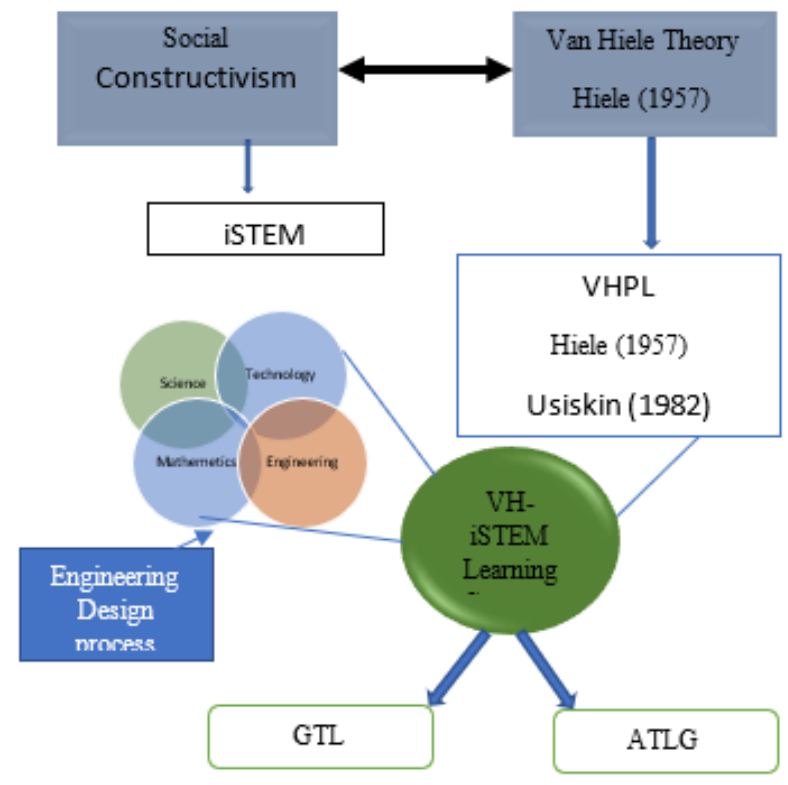

Fig. 6.Theoretical Framework

The framework for the development of VH-iSTEM basically is drawn from two theories that include social constructivism and van Hiele theory of learning geometry. However, social constructivism (Vygotskian) theory was built upon cognitive (Piagetian) believe or idea that child is an active learner, but Vygotsky gives emphasis on the social contexts that social interaction promote learning development [35]. According to the theory, the learning experience is developed and constructed based on social interaction, children and adult are the active agents in the child developmental process (Verenikina, 2010; Kalpana, 2014). According to Vygotsky meaningful learning occurs at a point called a Zone of Proximal Development (ZPD) and it is defined as the distance between actual development level and potential development level. 
The former is the individual problem solving and the latter is the problem solving under collaboration or guidance by the adult (ibid). in other words, both the teacher and learners can perform a task together in a classroom or informal setting which the learners cannot achieve independently through guide, support, or scaffolding.

Van Hiele theory is one of the best and well-articulated theories that can describe how learners, learn geometry and give better explanation of their levels of geometric thinking , better understanding of geometry and develop higher levels thinking of the learners in geometry through phases of instruction proposed by the theory (Clements, 2003; Abdullah et al., 2014; Abdullah \& Zakaria, 2013b Sinclair et al., 2016).

The social constructivism shared some common elements with VHTG in the instructional process, among the common elements, for example, is the role of the teacher in the instructional process, is considered as a facilitator who can only coordinate learning through discussion with the learners to discover certain structure [11]. The learning approach is student-centered both VHTG and social constructivism give emphasis on the child-centered activity where learners are given opportunities to harness their prior experience to create their own activities in order to give meaning out of what they learn and generate new knowledge as a result of teacher scaffolding. Hiele (1999) emphasized this in the integration phase of VPL. Another important connection between social constructivism and VHTG is language. Hiele is of the believed that language structure is one of the major factors needed in the movement of the learners through the levels of geometric thinking as explained [40]. Moreso, each level has its own linguistic symbols and its own system of relations connecting these symbols (Ibid, page 427). In the same vein, social constructivism considers cultural artifact and more importantly the language as need mediated tools. The language could be the learners' first language or a language familiar and understand by the learners, which can be used to exemplify and help them to make meaning and develop new knowledge.

However, the iSTEM approach (engineering design phase) share the same process and was developed based on social constructivism theory [41]. It also considered as a pedagogical strategy that is used in problem-solving, and development of concepts in science and mathematics (geometry in particular), this can be done in many ways, such as model representations, pictures, to develop creative thinking skills (ibid). while van Hiele phases are the creation of the van Hiele theory which supported the above mention process.

\section{RESEARCH METHODOLOGY}

The present research employed both qualitative and quantitative data to elucidate the experts' validation of the VH-iSTEM learning strategy prior to the final implementation of the strategy in the classroom. Thus, quantitative data were also obtained to further verified the effectiveness of the learning strategy by giving pre-test and post-test to students in the pilot study.

However, the content of the module, lesson activity was shared and discussed with the 5 experts in order to provide their comments, base on connections establish between engineering design and van Hiele phases on the VH-iSTEM learning strategy. Thus, their comments and suggestions were given consideration in order to actualize the objectives of the research. More so qualitative data were obtained based on the interview with three experts in order to obtained more comments and suggestions about the connections of the two phases of learning strategy. On top of that experts' evaluation forms were given to five experts to evaluate the learning strategy as explained above. Stemler [42] indicated that a rate of $75 \%$ to $90 \%$ is acceptable, and Bajpai, Bajpai, \& Chaturvedi [43] affirmed that it demonstrated an acceptable rate.

\section{A. Research instruments}

To gain the validity of a module Meryer in Wahab et al [34], suggested the conduct of simple analysis to determine the quality and effectiveness of activity develop in learning strategy. To achieve this, evaluation forms were provided to experts to rate the content, based on its objectives, sufficiency, students-center, the integration of STEM with strategy, and also based on lesson activity organization that covers, connections between iSTEM and van Hiele phases of learning geometry; collaborative and independent learning on the activities, orderliness in the connection of the phases in VH-iSTEM learning strategy. Thus, the van Hiele test of geometric thinking was used, where 15 questions were adopted with permission. Substantial research used the test to determine the students' level of geometric thinking [7], [34], [44].

\section{B. Sample}

The sample of the study involves the two sets of the subject, that include five (5) experts to evaluate the content of the learning strategy, where three (3) were engaged in an interview to elucidate more information from their suggestions and comments. The second subject was students, where 30 students are involved in a pilot study to determine the effectiveness of activities as well as the quality of the strategy prior to the final implementation. This was done in order to observe problems, and difficulties that may occur and provide corrections if any found before the actual implementation.

\section{RESULT AND DISCUSSION}

This section provides the findings and analysis of results obtained based on the rating for the validation of five (5) experts, on two sections provided in the experts' validation form. This includes content validation and content and lesson organization and evaluation of students' level of geometric thinking based on the outcomes of pre and post-test in the pilot study.

\section{A. Content validation based on VH-iSTEM Learning Strategy}


The table 1 below shows percentages evaluation obtained from the result of expert rating, where a high evaluation percentage were given by the experts based on the content. Moreover, it shows that the organization of the content is sufficient, aligns; with objectives; provides students the opportunity to solve the problem with their own ideas; and sufficiency in the integration of STEM activities.

Table - I Summary of the content validation based on the experts rating om VH-STEM learning strategy

\begin{tabular}{|c|c|c|c|c|c|c|c|}
\hline Content validation & $\begin{array}{l}\text { Expert } \\
1\end{array}$ & $\begin{array}{l}\text { Expert } \\
2\end{array}$ & \begin{tabular}{l|} 
Exper \\
3 \\
\end{tabular} & $\begin{array}{l}\text { Expert } \\
4\end{array}$ & \begin{tabular}{l|} 
Exper \\
5 \\
\end{tabular} & Mean & $\begin{array}{l}\text { Percent } \\
(\%)\end{array}$ \\
\hline $\begin{array}{l}\text { Sufficiency in the scope of the contents in realizing } \\
\text { the purpose of the research. }\end{array}$ & 3 & 5 & 4 & 4 & 4 & 4.00 & 80 \\
\hline Alignment of the objectives with the content. & 3 & 5 & 4 & 4 & 3 & 3.80 & 76 \\
\hline $\begin{array}{l}\text { The content in VH-iSTEM provides \& gives } \\
\text { students the opportunity to solve problems with their } \\
\text { own ideas. }\end{array}$ & 4 & 5 & 4 & 4 & 3 & 4.00 & 76 \\
\hline $\begin{array}{l}\text { Integration of STEM activity with VH-iSTEM is } \\
\text { sufficient }\end{array}$ & 4 & 5 & 4 & 4 & 3 & 4.00 & 80 \\
\hline $\begin{array}{l}\text { Appropriateness of the content and activities of } \\
\text { VH-iSTEM with 12-13 years students. }\end{array}$ & 4 & 5 & 4 & 4 & 3 & 4.00 & 76 \\
\hline
\end{tabular}

\section{$\mathrm{N}=5$}

\section{B. Content and lesson organization in VH-iSTEM learning strategy}

Table 2 below shows the percentage ratings based on the feedback of the experts; the results show a percentage of $80 \%$ to $84 \%$. Therefore, it shows that the content and lesson activities organization in VH-iSTEM learning strategy is appropriate, with the lesson objectives; the connections between the phases are appropriate. Furthermore, those activities in the VH-iSTEM learning strategy encourages collaborative and independent learning, the material used in the activities and orderliness of the phases are compatible.

Table -II Summary of content and lesson organization based on experts rating on VH-iSTEM

\begin{tabular}{|l|l|l|l|l|l|l|l|}
\hline Content and Lesson Organization & $\begin{array}{l}\text { Expert } \\
\text { Expert }\end{array}$ & $\begin{array}{l}\text { Expert } \\
\mathbf{2}\end{array}$ & $\begin{array}{l}\text { Expert } \\
\mathbf{3}\end{array}$ & $\begin{array}{l}\text { Expert } \\
\mathbf{5}\end{array}$ & $\begin{array}{l}\text { Mean } \\
\text { Percent } \\
(\%)\end{array}$ \\
\hline $\begin{array}{l}\text { Appropriateness of the lesson objectives. } \\
\text { the connection between STEM and van Hiele phase of } \\
\text { learning in the lesson activities of the VH-iSTEM } \\
\text { learning strategy. }\end{array}$ & 4 & 5 & 4 & 4 & 4 & 4.20 & 84 \\
\hline $\begin{array}{l}\text { The activity in VH-iSTEM can encourage collaborative } \\
\text { \& independent learning. }\end{array}$ & 4 & 5 & 4 & 4 & 3 & 3 & 8.00 \\
\hline $\begin{array}{l}\text { appropriateness of learning materials in the lesson } \\
\text { activities. }\end{array}$ & 4 & 5 & 4 & 4 & 4 & 4.00 & 80 \\
\hline $\begin{array}{l}\text { Orderliness in the connection of the phases in the } \\
\text { VH-iSTEM. }\end{array}$ & 3 & 5 & 4 & 4 & 4 & 8.20 & 84 \\
\hline
\end{tabular}

$\mathrm{N}=5$

However, to further confirmed the above feedback of experts' rating the scores from the experts' feedback were subjected to the intraclass correlation coefficient of the two-way random-effects model, with the Percentage Absolute Agreement (PAA) was computed based on the feedback of five experts on the 10 items. The results indicated an average Measure of 0.97 which is considered and interpreted as good. Following this a qualitative data was obtained from three themes, the table-III below provides the result for the interclass correlation coefficients. 
Design and Development of VH-iSTEM Learning Strategy on Geometric Thinking: An Experts' Evaluation

Table-III. Intraclass Correlation Coefficient

\begin{tabular}{|l|l|l|l|l|l|l|l|}
\hline & Intraclass & \multicolumn{5}{|l|}{$95 \%$ Confidence Interval } & \multicolumn{4}{|l|}{ F Test with True Value 0 } \\
\cline { 2 - 8 } & Correlation & Lower Bound & Upper Bound & Value & df1 & df2 & Sig \\
\hline Single Measures & $.778^{\mathrm{a}}$ & .515 & .968 & 33.245 & 4 & 36 & .000 \\
\hline Average Measures & .972 & .914 & .997 & 33.245 & 4 & 36 & .000 \\
\hline
\end{tabular}

Table -IV. provides the qualitative data from the expert, the interview was transcribed based on three themes that include the connections between the phase of iSTEM (engineering design phase) and van Hiele phases; the content; and finally, the development of geometric thinking. The results obtained from the feedback affirmed experts' evaluation of the VH-iSTEM from the quantitative data obtained.

Table-V. Questions and responses from the experts' interview about VH-iSTEM learning strategy

\begin{tabular}{ll}
\hline S/ & Questions \\
\hline 1 & \multicolumn{1}{c}{ What can you say about } \\
& the connection between van \\
& Hiele phase of learning \\
& geometry with components \\
& of iSTEM provided in \\
& VH=iSTEM?
\end{tabular}

2 Do you think that the content is in line with the Nigerian Mathematics Curriculum?

3 Do you think that the activities provided in VH-iSTEM are suitable for developing or improving geometric thinking?
Responses obtained

Themes

$\mathbf{R}_{1}, \ldots$. There is link ... and all what is in the phase are the replicants of van Hiele phases ( $\boldsymbol{R}_{\mathbf{2}}$ ) $\boldsymbol{O} \boldsymbol{k}_{\ldots}$ one can say in general term there are direct connections between the two ......if I can say in one sentence..... and added they are quite appropriate $\&$ suitable because of the connection of phases. $\boldsymbol{R}_{3}, \ldots$ yes, there is interconnection and interplay between the two in such a way that the learning can take place.

$R_{1}$, I believe the content is in line....

Content

$\boldsymbol{R}_{\mathbf{2}}$ yes, it is extracted directly from the content of the Nigerian Mathematics curriculum .....

$\ldots \boldsymbol{R}_{3}$ yes, it's quite in line with the content of the mathematics curriculum ....

$\boldsymbol{R}_{1}$ yes, because if the chance is given to students to discourse and discover by themselves... a... a..... I think they will appreciate it and can develop their thinking.

$\boldsymbol{R}_{\mathbf{2}}$ Yes, of course, because the activities can stimulate thinking by using questions to extract meaning out of their activity...... so yes.

$\boldsymbol{R}_{\mathbf{3}}$ yes, I believe if you follow the activity and provide a better learning environment, the thinking of the learners can improve.
Development of geometric thinking

\section{Students levels of geometric thinking}

The results obtained from the analysis of pre and post-test of geometric thinking test indicated that VH-iSTEM provided the need objectivities by improving the levels of students' geometric thinking skills as shown in Table 6 below. The table indicates that students' levels of van Hiele geometric thinking increased, where Eighteen (18) students representing $60 \%$ increased from level 0 to level 1 and two (2) students presenting $6.7 \%$ from level 0 to level 2; also two (2) students or $6.7 \%$ increased from level 1 to level 2; three students (3) or $10 \%$ increased from level 1 to level 3. However, four (4) students remained at level 0 out of 20 students in the pre-test.

\section{Connections}

between the phases 
Table -VI changes in the pre and post-test on student levels of geometric thinking

\begin{tabular}{|c|l|l|}
\hline \multirow{2}{*}{$\begin{array}{l}\text { Changes in the levels of } \\
\text { thinking }\end{array}$} & \multicolumn{2}{|c|}{ VH-iSTEM } \\
\cline { 2 - 3 } & Freq. & $\%$ \\
\hline Level 0 - Level 0 & 4 & $13.3 \%$ \\
\hline Level 0 - Level 1 & 18 & $60 \%$ \\
\hline Level 0 - Level 2 & 2 & $6.7 \%$ \\
\hline Level 0 - Level 3 & 0 & \\
\hline Level 1 - Level 0 & 0 & \\
\hline Level 1 - Level 1 & 1 & $3.3 \%$ \\
\hline Level 1 - Level 2 & 2 & $6.7 \%$ \\
\hline Level 1 - Level 3 & 3 & $10 \%$ \\
\hline
\end{tabular}

The connections of two learning strategy were emphasized in this study, that is the connection of iSTEM approach that includes engineering design phase (ask, imagine, plan, create, and improve) and van Hile phase (information, guided orientation, explanation, free orientation, and integration). Thus the former provides the learners the opportunity to develop their own knowledge based on experiments or activities and reach their own conclusion [28]. Kelley \& Knowles [29], indicated that the iSTEM approach provides a learning strategy that learners can develop learning experience or skills through activities. Hiele,[11] indicated that students can understand geometry that was developed by Euclid if and only if the students were given the opportunity to play, Construct, patterns and hands-on activity. And maintained that in this process learners can reach to more advanced level of geometric thinking skills (ibid).

Therefore, the development of VH-iSTEM learning strategy lesson activities was provided based on the connections of the two-phased. The findings from the feedback of the experts for suitability of the connections of the phases had $80 \%$ agreements of the experts and that also $80 \%$ agreements were obtained for the Orderliness in the connection of the phases. And that the activities can encourage collaborative and independent learning. Evidence abounds [28] that, students learn not only from their teacher but also from their peers and this kind of learning process encourages critical thinking. Shahali et al [41] indicated that the engineering design phase is one of the iSTEM approaches that bridged the gap among STEM subjects. Besides that, the engineering design process is an impetus that can help students to develop a contextual understanding of mathematics and science through the use of concrete models, symbols and pictures to develop real-world representation (ibid). In general, the overall evaluation, shows, a positive response from the experts and an increased in students' geometric thinking from a lower level to a more sophisticated level was discovered.

The results confirmed that VH-iSTEM learning strategy achieved its objectives by improving the levels of geometric thinking skills of the students. It therefore, can be concluded that VH-iSTEM can be used in learning school geometry and can be used in further research to investigated its effectiveness in relation to other approaches.

\section{REFERENCE}

1. G. Georg, Geometry and its Applications in Arts, Nature and Technology. Austria: Springer-Verlag/Wien, 2012.

2. A. H. Abdullah and E. Zakaria, "The Effects of Van Hiele's Phases of Learning Geometry on Students' Degree of Acquisition of Van Hiele Levels," Procedia - Soc. Behav. Sci., vol. 102, no. November, pp. 251-266, 2013.

3. L. S. Gronmo, M. Lindquist, A. Arora, and I. V. S. Mullis, "TIMMS 2015 Mathematics Framework," in TIMSS 2015 International Results in Mathematics, 2016, pp. 11-27.

4. I. Carl, "Essential mathematics for the twenty-first century: the position of the National Council of Supervisors of Mathematics," Jstor, vol. 82, no. 6, pp. 470-474, 1989.

5. D. Fuys, "Van Hiele Levels of Thinking in Geometry," Educ. Urban Soc., vol. 17, no. 4, pp. 447-462, 1985

6. G. C. Ogan and N. R. George, "Investigating Difficult Concepts in Senior Secondary School Mathematics Curriculum as Perceived by Students," Int. J. Acad. Res. Reflect., vol. 3, no. 6, pp. 67-74, 2015.

7. J. K. Alex and K. J. Mammen, "Lessons Learnt from Employing van Hiele Theory Based Instruction in Senior Secondary School Geometry Classrooms," EURASIA J. Math. Sci. Technol. Educ., vol. 12, no. 10, pp. 2223-2236, 2016.

8. Z. Usiskin, "Van Hiele Levels and Achievement in Secondary School Geometry. CDASSG Project.” Chicago USA, p. 321, 1982.

9. I. Vojkuvkova, "The van Hiele Model of Geometric Thinking," in WDS'12 Proceedings of Contributed Papers, 2012, vol. 1, pp. $72-75$.

10. F. Federal Repulic of Nigeria, "Basic Education Mathematics Curriculum.pdf." Nigerian Educational Research and Development Council (NERDC), Abuja, p. 36, 2012.

11. P. M. Van Hiele, "Developing Geometric Thinking Activities That Begin with Play," J. Natl. Counc. Teach. Math., vol. 5, no. 6, pp. 310-316, 1999.

12. H. . Atebe, "Students' Van Hiele Levels of Geometric Thought and Conception in Plane Geometry: a Collective Case Study of Nigeria and South Africa," RHODES UNIVERSITY, 2008.

13. WAEC Chief Examiner, "The West African Examinations Council Offline E- Registration and Chief Examiner's Report,May/June,2008 CD Produced by Sidmach Technology Nig, Ltd.” 2008.

14. WAEC Chief Examiner, The West African Examinations Council Offline E-Registration and Chief Examiner's Report May/June 2010, CD Produced by Sidmach Technology Nig, Ltd. 2010.

15. WAEC Chief Examiner, "The West African Examinations Council Offline E- Registration and Chief Examiner's Report Nov/Dec,2010, CD Produced by Sidmach Technology Nig, Ltd.” 2010.

16. WAEC Chief Examiner, The West African Examinations Council Offline E-Registration and Chief Examiner's Report Nov/Dec,2011, CD Produced by Sidmach Technology Nig, Ltd. 2011.

17. WAEC Chief Examiner, "The West African Examinations Council Offline E- Registration and Chief Examiner's Report May/June,2012, CD Produced by Sidmach Technology Nig, Ltd.," 2012.

18. WAEC Chief Examiner, "The West African Examinations Council Offline E- Registration and Chief Examiner's Report May/June,2014, CD Produced by Sidmach Technology Nig, Ltd.,' 2014.

19. B. F. Azuka, "Effect of the Acquistion of Emotional Intelligence Skills on the Interest of Senior Secondary School Students in Geometry," J. Math. Sci., vol. 3, no. 1, pp. 421-435, 2014.

20. H. U. Atebe and M. Schäfer, "The nature of geometry instruction and observed learning-outcomes opportunities in nigerian and south african high schools," African J. Res. Math. Sci. Technol. Educ., vol. 15, no. 2, pp. 191-204, 2011

21. B. I. Nwoke, "Enhancing Secondary School Students' Achievement in Mathematics Using Peer Tutoring Instructional Approach," Abacus, The J. Math. Assoc. Nriaige, vol. 42, no. 1, pp. 406-416, 2017.

22. E. C. Unamba, O. M. Nwaneri, and N. Nelson, "Effectiveness of Brain-Based Learning Approach on Puplis Academic Achievement in Mathematics," Abacus,The J. Math. Assoc. Nriaige, vol. 42, no. 1, pp. 551-559, 2017. 
23. D. B. Thomas, "Effects of Generative Learning Strategy on Students' Understanding and Performance in Geometry in Lafia Metroplis, Nasarawa State, Nigeria," Abacus, The J. Math. Assoc. Nriaige, vol. 42, no. 2, pp. 16-25, 2017.

24. B. Andy, F. Geoff, W. Sue Johnston, L. R. Francis, J. Mason, and W. Geoff, Developing Thinking in Geometry. London: Paul Chapman Publishing A SAGE Publiction Company 1 Oliver's Yard 55 City Road, London EC1Y 1 SP Inc 2455, 2005.

25. J. Van de Walle, "Geometric thinking and geometric concepts," in Elementary and Middle school mathematics: Teaching developmentally., 4th ed., Boston.Allyn and Bacon, Eds. Peason Education, 2004, pp. 306-312.

26. L. O. Adetula, "www.ijcer.net National Mathematical Centre Mathematics Improvement Project (NMC-MIP): A Project Transforming The Mathematics Performance Of Students National Mathematical Centre - Mathematics Improvement Project (NMC-MIP): A Project Transforming the Mat," Int. J. Contemp. Educ. Res., vol. 2, no. 2, pp. 104-117, 2015.

27. D. s. Dorojaiye, M. F. Salman, O. J. Jekayinfa, and S. O. Okwuoza, "Effects of Activity Based Instructional Strategy on Senior Schoo students' Performance in Circle Geometry in Abuja, Nigeria," $J$. Math. Sci. Natl. Math. Cent. Abuja Niger., vol. 4, no. 1, pp. 577-590, 2016.

28. M. A. Wasagu, "Innovation in STEM Education: The Missing Link in Nigeria," in Innovation in STEM Education 60th Annual Conference by Science Teachers Association of Nigeria (STAN), 2019, pp. 3-26.

29. T. R. Kelley and J. G. Knowles, "A conceptual framework for integrated STEM education," Int. J. STEM Educ., vol. 3, no. 1, p. 11, 2016.

30. (ELSA) Australian Government Department of Education and Training under the Early Learning STEM Australia, "Early Learning in STEM Multimodal learning in the 21st Century," Melbourne, Australia, 2016.

31. (G S A) Global STEM Alliance, "STEM Education Framework." The New York Academy of Science, p. 30, 2016.

32. L. Cheung, "Using the ADDIE Model of Instructional Design to Teach Chest Radiograph Interpretation," J. Biomed. Educ., vol. 2016 , pp. 1-6, 2016.

33. M. A. Yusha, "Effective Use of Teaching Methodologies in Science, Technology and Mathematics ( STM ) Classroom in Nigeria: A Panacea to Vision 20 : 2020," Int. J. Educ. Pract., vol. 3, no. 3, pp. 114-121, 2015.

34. R. A. Wahab, A. H. Abdullah, M. Mokhtar, N. A. Atan, and M. S. $\mathrm{Abu}$, "Evaluation by experts and designated users on the learning strategy using sketchup make for elevating visual spatial skills and geometry thinking," Bolema - Math. Educ. Bull., vol. 31, no. 58, pp. 819-840, 2017.

35. I. M. Verenikina, "Vygotsky in Twenty-First-Century research," in Proceedings of World Conference on Educational Multimedia, Hypermedia and Telecommunications, 2010, pp. 16-25.

36. T. Kalpana, "A Constructivist Perspective on Teaching and Learning : A Conceptual Framework," Int. Res. J. Soc. Sci., vol. 3, no. 1, pp. 27-29, 2014.

37. D. H. Clements, "Teaching and learning geometry," in A Research Companion to Priciples and Standards for School Mathematics, New York, 2003, pp. 151-178.

38. A. H. Abdullah, N. H. Ibrahim, J. Surif, and E. Zakaria, "The effects of Van Hiele's phase-based learning on students' geometric achievement and attitude towards geometry," Proc. - 2014 Int. Conf. Teach. Learn. Comput. Eng. LATICE 2014, pp. 317-324, 2014.

39. N. Sinclair et al., "Recent research on geometry education: an ICME-13 survey team report," ZDM - Math. Educ., vol. 48, no. 5, pp. 691-719, 2016

40. D. H. Clements and M. T. Battista, "Geometry and Spatial Reasining: Handbook of Research on Mathematics Teaching and Learning.' Macmillan, New York, p. 464, 1992.

41. E. H. M. Shahali, L. Halim, M. S. Rasul, K. Osman, and M. A. Zulkifeli, "STEM learning through engineering design: Impact on middle secondary students' interest towards STEM," Eurasia J. Math. Sci. Technol. Educ., vol. 13, no. 5, pp. 1189-1211, 2017.

42. S. E. Stemler, "A Comparison of Consensus, Consistency, and Measurement Approaches to Estimating Interrater Reliability Practical Assessment, Research \& Evaluation," Pract. Assessment, Res. Eval., vol. 9, no. 4, pp. 1-11, 2004.

43. S. Bajpai, R. Bajpai, and H. K. Chaturvedi, "Evaluation of Inter-Rater Agreement and Inter-Rater Reliability for Observational Data: An Overview of Concepts and Methods Evaluation of
Inter-Rater Agreement and Inter-Rater Reliability for Observational Data : An Overview of Concepts and Methods," J. Indian Acad. Appl. Psychol., vol. 14, no. March, pp. 20-27, 2015.

44. A. H. Abdullah, J. Surif, L. M. Tahir, N. H. Ibrahim, and E. Zakaria, "Enhancing Students' Geometrical Thinking Levels through Van Hiele's Phase-Based Geometer's Sketchpad-Aided Learning," in 2015 IEEE 7th International Conference on Engineering Education (ICEED), 2015, no. 4, pp. 106-111.

\section{AUTHORS PROFILE}

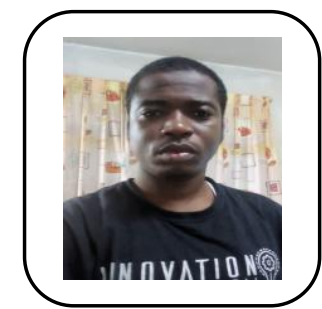

Hassan Muhammad Nasiru, Postgraduate Student in Mathematics Education at Universiti Teknologi Malaysia (UTM), Malaysia, School of Education, department Science, Mathematics and Creative Multimedia education.

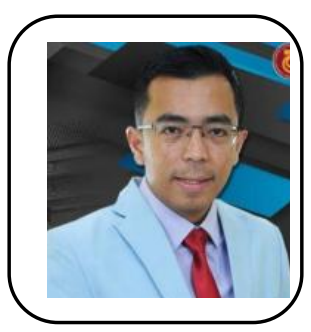

Abdul Halim Abdullah, He is currently an Associate Professor in school of Education Universiti Teknologi Malaysia.

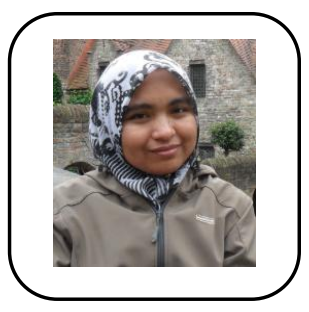

Ismail Norulhuda, She is currently a Senior lecturer in School of Education, Universiti Teknologi Malaysia. 